\title{
Article
}

\section{Toward halogen-free flame resistant polyethylene extrusion coated paper facings}

Pawelec, Weronika, Tirri, Teija, Aubert, Mélanie, Häggblom, Eva, Lehikoinen, Tommi, Skåtar, Rune, Pfaendner, Rudolf and Wilén, Carl-Eric

Available at http://clok.uclan.ac.uk/13641/

Pawelec, Weronika, Tirri, Teija, Aubert, Mélanie, Häggblom, Eva, Lehikoinen, Tommi, Skåtar, Rune, Pfaendner, Rudolf and Wilén, Carl-Eric (2015) Toward halogen-free flame resistant polyethylene extrusion coated paper facings. Progress in Organic Coatings, 78 . pp. 67-72. ISSN 0300-9440

It is advisable to refer to the publisher's version if you intend to cite from the work. http://dx.doi.org/10.1016/j.porgcoat.2014.10.005

For more information about UCLan's research in this area go to http://www.uclan.ac.uk/researchgroups/ and search for <name of research Group>.

For information about Research generally at UCLan please go to http://www.uclan.ac.uk/research/

All outputs in CLoK are protected by Intellectual Property Rights law, including Copyright law. Copyright, IPR and Moral Rights for the works on this site are retained by the individual authors and/or other copyright owners. Terms and conditions for use of this material are defined in the policies page.

\section{CLoK}

Central Lancashire online Knowledge www.clok.uclan.ac.uk

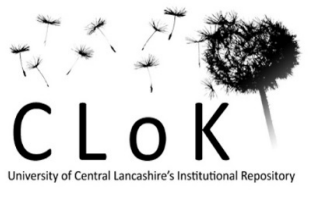


A. Witkowski, B. Girardin, M. Försth, F. Hewitt, G. Fontaine, S. Duquesne, S. Bourbigot, T. R. Hull, "Development of an Anaerobic Pyrolysis Model for Fire Retardant Cable Sheathing Materials", Polymer Degradation and Stability, 113, 208-217, 2015.

\section{Development of an Anaerobic Pyrolysis Model for Fire Retardant Cable Sheathing Materials}

Artur Witkowski ${ }^{a, *}$, Bertrand Girardin ${ }^{b}$, Michael Försth ${ }^{c, d}$, Fiona Hewitt ${ }^{a}$, Gaëlle Fontaine ${ }^{b}$, Sophie Duquesne ${ }^{b}$, Serge Bourbigot $^{\mathrm{b}}$, T. Richard Hull ${ }^{\mathrm{a}}$

${ }^{a}$ Centre for Fire and Hazards Science, University of Central Lancashire (UCLan), Preston PR1 2HE, UK

${ }^{\text {b }}{ }_{2}$ Fire / UMET - UMR CNRS 8207, ENSCL, Avenue Dimitri Mendeleïev - Bât. C7a, CS 90108, 59652 Villeneuve d'Ascq, France

'SP Fire Research, SP Technical Research Institute of Sweden, P.O. Box 857, SE-501 15 Borås, Sweden

${ }^{\mathrm{d} D e p a r t m e n t}$ of Civil, Environmental and Natural Resources Engineering, Luleå University of Technology, SE-971 87

Luleå, Sweden

\section{Abstract}

Wire and cable coverings are potentially a major cause of fire in buildings and other installations. As they need to breach fire walls and are frequently located in vertical ducting, they have significant potential to increase the fire hazard. It is therefore important to understand the ignition and burning characteristics of cables by developing a model capable of predicting their burning behaviour for a range of scenarios. The fire performance of electrical cables is usually dominated by the fire performance of the sheathing materials. The complexity of the problem increases when cable sheathing incorporates fire retardants. One-dimensional pyrolysis models have been constructed for cable sheathing materials, based on milligram-scale and bench-scale test data by comparing the performance of three different software tools (ThermaKin, Comsol Multiphysics and FDS, version 6.0.1). Thermogravimetric analysis and differential scanning calorimetry were conducted on powdered cable coatings to determine the thermal degradation mechanism, the enthalpy of decomposition reactions, and the heat capacities of all apparent species. The emissivity and the in-depth absorption coefficient were determined using reflectance and transmittance measurements, with dispersive and non-dispersive spectrometers and integrating spheres. Bench-scale tests were conducted with a mass loss calorimeter flushed with nitrogen on samples in a horizontal orientation, for comparison with the pyrolysis model of non-flaming decomposition at an external heat flux of 50 $\mathrm{kW} \mathrm{m} \mathrm{m}^{-2}$. The parameters determined through analysis of the milligram-scale data were used to construct a pyrolysis model that predicted the total mass loss from calorimeter tests in anaerobic conditions. A condensed phase pyrolysis model that accurately predicts in-depth temperature profiles of a solid fuel, and the mass flux of volatiles evolved during degradation of the fuel, is an essential component of a comprehensive fire model, which when coupled to a computational fluid dynamics code can be used to predict the burning processes in a fire scenario. Pyrolysis models vary considerably in complexity based on the assumptions incorporated into the development of the model.

Key Words: pyrolysis; thermal decomposition kinetics; thermophysical properties; polymer cable; modelling; fire retardant.

*Corresponding author. E-mail address: awitkowski@uclan.ac.uk 


\section{Introduction}

Cable fires are a potential fire threat which attracts considerable attention from industry, researchers and regulators. The disastrous fires at King's Cross underground station in London, or at the Düsseldorf Airport in Germany, are two examples where cable fires contributed to the loss of lives and property [1,2]. Cable fires can start either by self-ignition [3] [4] or by exposure from external thermal heating. In both cases, it is the pyrolysis process of the polymeric sheathing and insulation materials which is responsible for the production of flammable pyrolysis products. It is this process that will determine whether or not enough volatile fuel is produced, for a given ignition scenario, to sustain a flame.

Much research is dedicated to developing fire-retardant cable sheathing and insulation materials with reduced flammability, longer time to ignition and lower heat release during pyrolysis. Polyvinyl chloride (PVC) was a major conventional cable material, but its high production of smoke and toxic/corrosive gas has led to many manufacturers seeking halogen-free, low smoke-producing replacements [5]. Polyolefins such as polyethylene (PE) and ethylene vinyl-acetate copolymer (EVA) meet these requirements while maintaining good flexibility and processability. However, their high flammability necessitates the incorporation of fire-retardants to make them fit for use as cable materials. Aluminium hydroxide (ATH) is a fire-retardant mineral filler that can be combined with materials like PE, but the proportion of components must be carefully controlled to ensure the balance between reduced flammability and retain desirable mechanical properties. During the development of such materials, it is important to have an understanding of the reaction to fire, and the effect that varying the components has on this. Conducting experiments to extract this information can be expensive and time-consuming.

Pyrolysis models can be useful in for determining fire-retardant mechanisms and understanding a material's fire behaviour. They are currently being developed with the aim that the fire behaviour of materials can be predicted, with respect to several flammability properties including time to ignition, avoiding the cost and complexities associated with large scale tests. Such models characterise samples using physical, thermal and kinetic parameters. The results from the models are compared with experimental results from micro-scale or bench-scale tests to evaluate the accuracy of the simulations. Several studies previously conducted have successfully modelled mass loss and heat release histories of charring and non-charring polymers exposed to external heat flux $[6,7,8,9]$.

Similar studies on fire-retarded materials are limited, and additional considerations must be made; such additives have a large impact on the physical and chemical behaviour of materials when heated. Kempel et al. [10] presented a study investigating the capability of the Fire Dynamics Simulator (FDS) and Thermakin models to predict the complex pyrolysis and thus fire behaviour of polymeric materials like poly (butylene terephthalate) (PBT) and PBT reinforced with 30\% glass fibres (PBT-GF). The comparison of simulations and experiments showed good agreement for the $\mathrm{PBT}$, but there were some limitations of the simulation of the residue-forming material PBT-GF.

Modelling of the full cable entity presents further challenges as the structure and geometry can be irregular and difficult to define. Several studies have tackled these challenges and can be found in the literature 
[11][12][13][14]. However, this work is focussed on defining and modelling the fire response of a cable sheathing material only.

An important feature of this study is that all parameters that are important for pyrolysis modelling were carefully determined experimentally, as opposed to estimated or extracted from the literature. This approach is relatively new and was demonstrated by McKinnon using corrugated cardboard [15]. Obtaining the input parameters in this way leads to a model that is more likely to physically represent the decomposition processes ongoing in the samples.

The pyrolysis model is implemented in three different numerical simulation tools: Thermakin, Comsol, and FDS, and their results are compared. Finally the models are compared with non-flaming experimental results from a nitrogen-flushed mass loss calorimeter. This work contributes to further understanding of the fire retardant behaviour of a common cable sheathing material and the comparison of three modelling tools allows their evaluation when parameters are experimentally determined.

\section{Experimental}

\subsection{Material and Sample Preparation}

The samples specific to this study were polyethylene (PE) filled with aluminium hydroxide (ATH) supplied by Leoni Studer AG (LS). The loading of ATH was $65 \% \pm 5 \%$.

The milligram-scale test methods required samples to be approximately uniform throughout with masses less than $10 \mathrm{mg}$. A grinder was used to powder the materials. All STA tests used powder samples prepared in this manner.

The bench-scale testing was conducted with a FTT mass loss calorimeter. All bench-scale tests conducted in the mass loss calorimeter used $3 \mathrm{~mm}$ thick, $100 \mathrm{~mm}$ x $100 \mathrm{~mm}$ samples. The samples were wrapped in heavy gauge aluminum foil such that one face of the sample was exposed to the radiant heat flux. Each sample was placed on top of $50 \mathrm{~mm}$ of insulating firebrick (IFP) JM26 ${ }^{\circledR}$ from Morgan Thermoceramics and positioned $25 \mathrm{~mm}$ from the cone heater surface for all bench-scale tests.

\section{$2.2 \quad$ Milligram-scale Testing}

Thermogravimetric analysis (TGA) and differential scanning calorimetry (DSC) tests were conducted with a Netzsch 449 F1 Jupiter and Stanton-Redcroft simultaneous thermal analysers (STA).

Temperature and sensitivity calibrations were conducted with each STA prior to testing. The temperature calibration relates the literature value of the melting temperatures of organic and inorganic samples to the melting temperature of the same materials measured by the apparatus. The sensitivity calibration relates the literature value of the enthalpy of melting of organic and inorganic samples to the measured enthalpy of melting of the same samples. The testing conditions and heating rate in the STA tests were identical to those used in the calibration procedures. More information concerning the calibration procedure for the STA apparatus is provided in a related work [16].

TGA tests were conducted in two different laboratories in an inert atmosphere to determine the chemical kinetics of the thermal degradation process. The powdered samples were compacted in platinum crucibles for TGA tests. 
The temperature program for the TGA tests was kept at a rate of $10{ }^{\circ} \mathrm{C} \mathrm{min}{ }^{-1}$. The nitrogen flow rate for all TGA tests was $50 \mathrm{~mL} \mathrm{~min}{ }^{-1}$. The heating rate of $10{ }^{\circ} \mathrm{C} \mathrm{min}-1$ was chosen because it is the most prevalent heating rate used in the literature $[9,16]$. This heating rate is low enough that the sample does not experience significant temperature or mass gradients, making the effects of mass and heat transfer negligible. Additional tests were conducted with different heating rates of $1,2,5,20,50,250$ and $500{ }^{\circ} \mathrm{C} \mathrm{min}^{-1}$ to test the sensitivity of the reaction mechanism defined in the model.

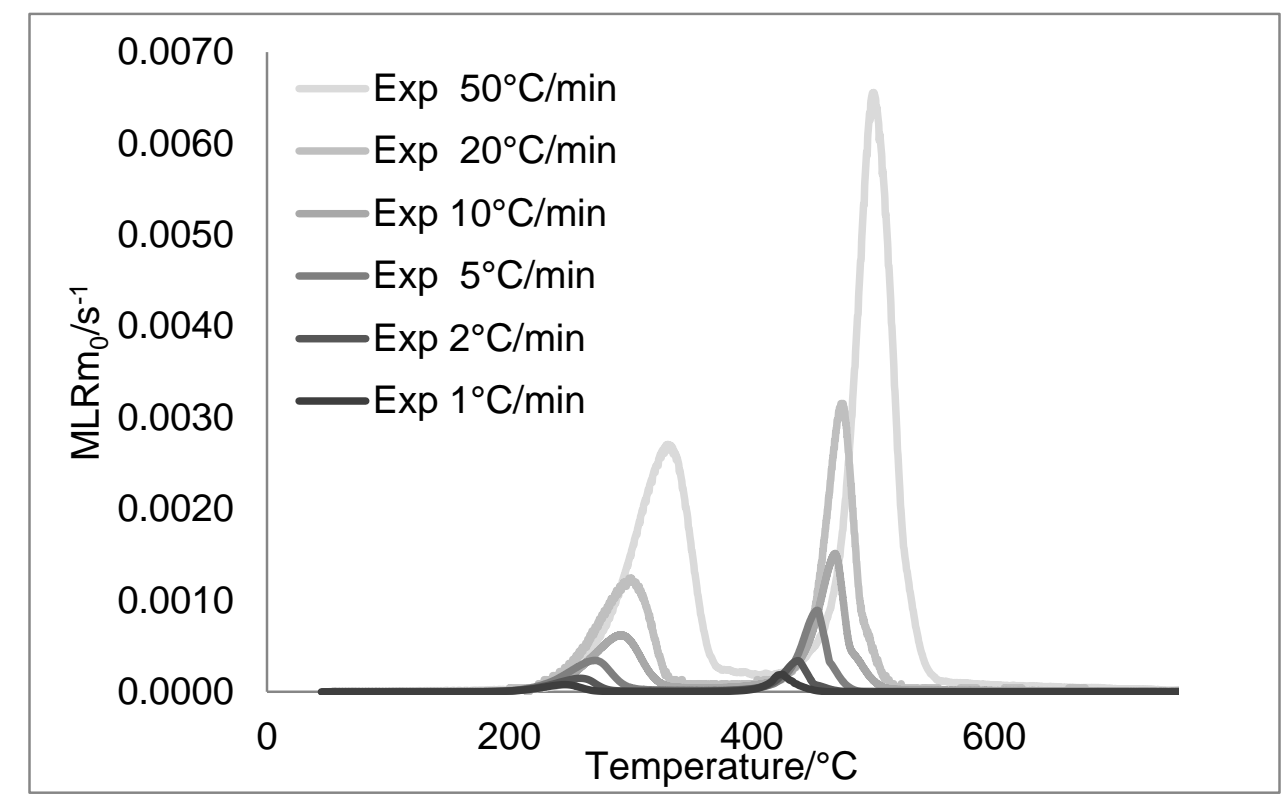

Figure 1: TGA Normalized Mass Loss Rate experimental data collected in nitrogen at a heating rates of 1,2 ,

$$
\text { 5, 10, } 20 \text { and } 50{ }^{\circ} \mathrm{C} \mathrm{min}^{-1} \text {. }
$$

The heat of the overall decomposition process and the heat capacities of the virgin material and char were determined from data collected by DSC using platinum/rhodium crucibles at a heating rate of $10^{\circ} \mathrm{C} \mathrm{min}{ }^{-1}$. The thermal conductivity of the materials was measured from $25{ }^{\circ} \mathrm{C}$ to $700{ }^{\circ} \mathrm{C}$ using a Hot Disk Thermal Constant Analyser (TPS 2500S) from Thermoconcept (Mérignac, France), using a transient plane source technique. The sensor, which is a heater and a thermocouple, is pressed between two $20 \times 20 \times 6 \mathrm{~mm}$ pieces of the material to ensure good contact between the sample and the sensor during the experiment. The assembly is then pressed between two steel sheets to maintain the contact between the sensor and the sample. The temperature is stabilised at $10^{\circ} \mathrm{C}$ increments below $100^{\circ} \mathrm{C}$, and $100^{\circ} \mathrm{C}$ increments from $100^{\circ} \mathrm{C}$ to $700{ }^{\circ} \mathrm{C}$, with precision of around $\pm 0.1^{\circ} \mathrm{C}$. The conductivity measurements were made by applying a power of 0.3 to $0.9 \mathrm{~W}$ for between 5 and $40 \mathrm{~s}$, depending on the thermal conductivity of the samples. The furnace was directly connected to a nitrogen flow and all experiments were carried out in an inert atmosphere to prevent oxidation of the sensor. This experimental set up allows measurement of a material's thermal conductivity as a function of temperature. 


\subsection{Bench-scale Testing}

The bench-scale testing was conducted using a Mass Loss Calorimeter from FTT (ISO 13927). This has an identical fire model and load cell to the cone calorimeter (ISO 5660). The main differences are that thermopiles are used to measure heat release (not reported here) and the facility exists to decompose specimens under anaerobic conditions, for which no standard currently exists. A special setup has been developed, isolating the cone heater and the sample, in order to control the atmosphere. The oxygen concentration was monitored using a zirconia oxygen analyser, BA1000 from Bühler Technologies.

Pyrolysis experiments were carried out with a controlled-atmosphere-mass-loss-calorimeter- (CAMLC) at the $\mathrm{R}^{2}$ Fire facilities. This test apparatus has been developed to study the influence of depleted oxygen environments on thermal degradation and combustion. The main difference from the standard test unit is the addition of an enclosure under the cone heater. This chamber consists of a stainless steel enclosure, with the standard cone heater at the top, a door with an observation window at the front and two gas inlet ports at the bottom (Figure 2 : A schematic representation of the (AMLC). The gas ports allow establishment of the desired oxygen and nitrogen concentration. The gas mixture is maintained at a suitably low flow rate through the enclosed chamber to facilitate the recirculation of combustion products over the specimen surface.

A truncated cone-shaped heater exposes the specimen to a constant irradiance level (up to $100 \mathrm{~kW} \mathrm{~m}^{-2}$ ). The spark igniter has been removed in this configuration as the released gases cannot ignite due to the nitrogen atmosphere. The effluents are collected in a hood and transported through a thermopile-equipped duct. The fire parameters that can be measured in the CAMLC under nitrogen are limited to mass loss and mass loss rate. 


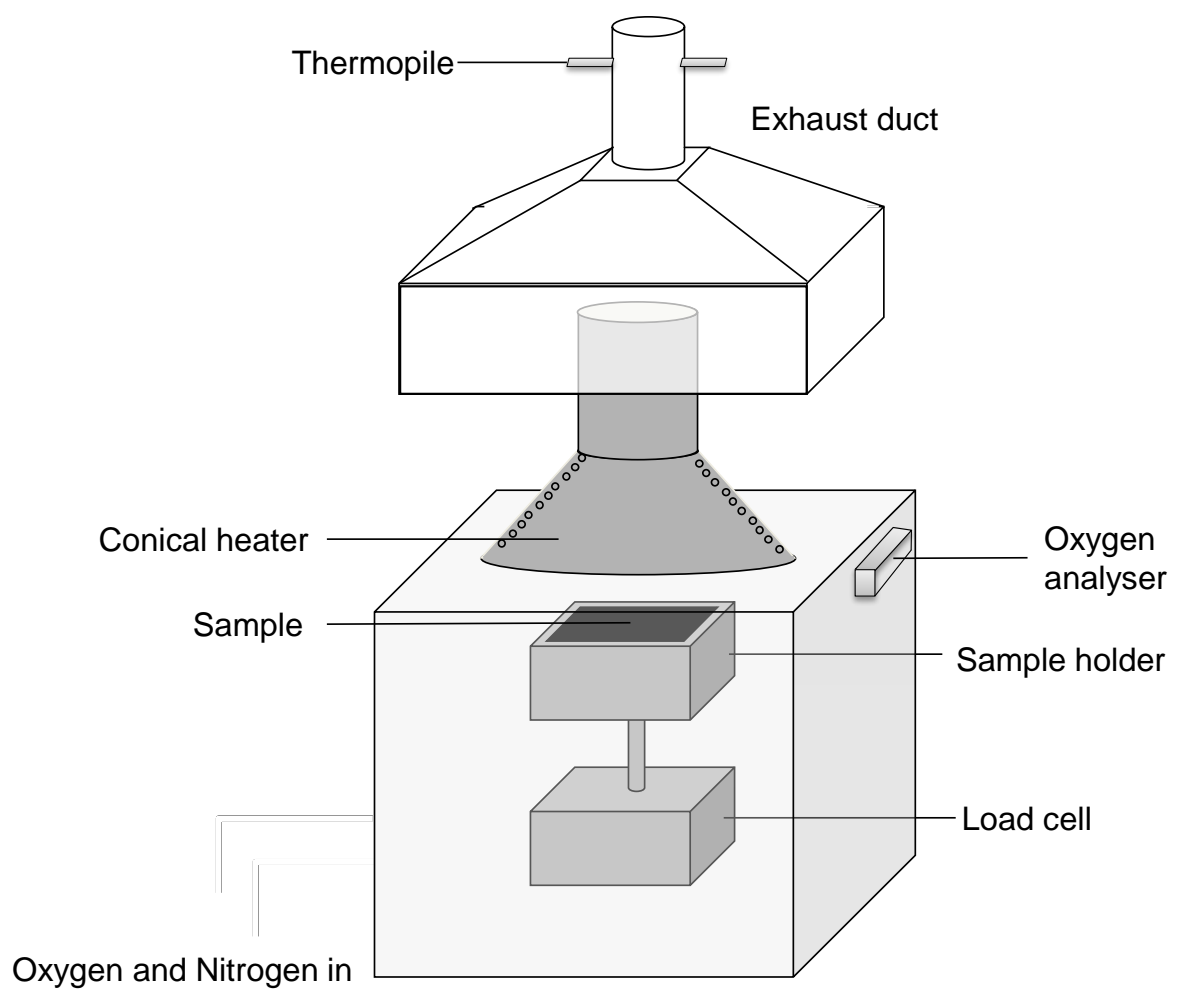

Figure 2 : A schematic representation of the CAMLC

\subsection{Infrared properties}

The radiative properties of importance for modelling are the surface absorptivity, $\alpha$, and the in-depth absorption coefficient, A. Once the total absorptivity is known, the surface emissivity is given by Kirchoff's law, $\varepsilon=\alpha$.

To be able to calculate the total absorptivity for incident radiation with different spectra, information is required on the spectrally resolved absorptivity, $\alpha_{\lambda}$. Direct absorptivity measurements are very difficult. Instead the reflectivity, $R_{\lambda}$, is measured. In cases when the transmittance, $T_{\lambda}$, is significant this property must also be measured. The spectral absorptivity is then calculated according to:

$$
\alpha_{\lambda}=1-R_{\lambda}-T_{\lambda}
$$

Spectra in the UV, visible and near IR region, with wavelengths in the interval 0.3 to $2.5 \mu \mathrm{m}$, were recorded using a Perkin Elmer Lambda 900 double beam spectrophotometer equipped with an integrating sphere. In the infrared wavelength range, with wavelengths in the interval 1.7 to $20 \mu \mathrm{m}$, a Bruker FTIR single beam spectrophotometer equipped with a gold coated integrating sphere was used. The principle of operation of an integrating sphere is shown in cross-section in Figure 3, with the incident beam entering the sphere through the port to the left and hitting the sample (or reference) covering the sample port to the right. The radiation from the sample surface is reflected multiple times inside the sphere. This illumination intensity is seen by the detector, which records a signal proportional to all the reflected light, including both the specular and diffuse parts. 


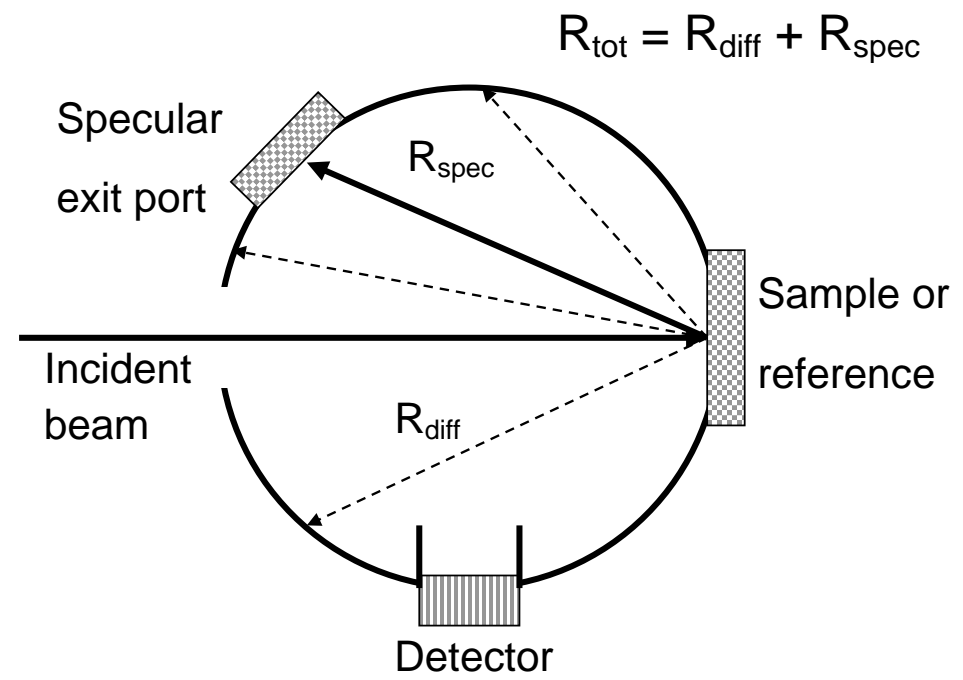

Figure 3: Principle of an integrating sphere.

Measurements were performed in a temperature stabilised laboratory with a temperature of $23^{\circ} \mathrm{C} \pm 2{ }^{\circ} \mathrm{C}$. The samples were conditioned in the laboratory one hour prior to the test. The accuracy of the reflectivity measurements was $\pm 3 \%$. Transmittance measurements are performed in a similar manner to the reflectance measurements described above, but with the sample positioned across the beam entry port in Figure 3 . For more details the reader is referred to reference [17].

The ratio between the total absorbed radiation and total incident radiation is given by the total absorptivity, $\alpha$. This is the spectrally averaged absorptivity, where the weight function is the exitance spectrum of the radiation source, $M_{\lambda}$, the heated coil of the cone calorimeter in this study.

$$
\alpha_{\text {eff }}=\frac{\int_{0}^{\infty} \alpha_{\lambda} M_{\lambda} d \lambda}{\int_{0}^{\infty} M_{\lambda} d \lambda}
$$

Boulet et al. [18] showed that the radiation from the cone calorimeter is well approximated by a black body spectrum. This is given by Planck's law:

$$
M_{\lambda}=\frac{2 \pi h c_{0}^{2}}{\lambda^{5}\left[\exp \left(\frac{h c_{0}}{\lambda k_{B} T}\right)-1\right]}
$$

where

$h$ is Planck's constant,

co is the speed of light in vacuum, 
$\lambda \quad$ is the wavelength.

While the transformation from spectrally resolved surface absorptivity to total surface absorptivity is straightforward using Eq. (2), the situation is more complex for the in-depth absorption coefficient, A. The spectrally resolved irradiance at a depth, $x$, into the sample is given by the Beer-Lambert law:

$$
I_{\lambda}(x)=I_{\lambda}(0) e^{-A_{\lambda} \cdot x}
$$

$A_{\lambda}$ is obtained from experimental measurements of the spectral transmittance.

$$
T_{\lambda}=\frac{I_{\lambda}(d)}{I_{\lambda}(0)}=e^{-A_{\lambda} \cdot d}
$$

where $d$ is the thickness of the investigated sample. The total irradiance at depth $x$ is obtained by integrating the contributions for all wavelengths:

$$
I(x)=\int I_{\lambda}(0) e^{-A_{\lambda} \cdot x} d \lambda
$$

For modelling, where only the total infrared properties can be handled, a total, spectrally independent, absorption coefficient is required. This is the parameter used in the standard expression for the Beer-Lambert law:

$$
I(x)=I(0) e^{-A \cdot x}
$$

Where $I(0)$ is the integral of the spectral irradiance over all wavelengths at the sample surface:

$$
I(0)=\int I_{\lambda}(0) d \lambda
$$

Comparing Eqs. (6) and (7), and inserting Eq. (8), we obtain:

$$
A=-\frac{1}{x} \cdot \ln \left(\frac{\int I_{\lambda}(0) e^{-A_{\lambda} \cdot x} d \lambda}{\int I_{\lambda}(0) d \lambda}\right)
$$

The total absorption coefficient is dependent on the depth, $x$. The parts of the radiation where the spectrally resolved absorption coefficient is high will rapidly be absorbed near the surface. As the radiation penetrates the sample the radiation spectrum will be distorted such that relatively more energy is concentrated to the wavelengths where the absorption coefficient is lower. It should be noticed that the absorption coefficient, A, given by Eq. (9), is not the local absorption coefficient at depth $x$. Instead, A is the parameter that gives the correct total irradiance at depth $x$ given an irradiation spectrum $I_{\lambda}(0)$ at the sample surface. 
The choice of depth $x$ in Eq. (9) is somewhat arbitrary but we propose to use the depth where the total irradiation has decreased to $\mathrm{e}^{-2} \approx 0.135$. This depth is sometimes referred to as the skin depth, or the penetration depth of the electromagnetic field. This absorption coefficient can be obtained by an iterative procedure using Eqs. (7) and (9).

\section{Pyrolysis Model}

ThermaKin [19], Comsol [20] and FDS [21] modelling tools were used in this investigation, during analysis of experimental data, to construct a one-dimensional model to predict the results from a nitrogen-flushed mass loss calorimeter.

In ThermaKin, non-steady energy and mass conservation equations are solved, accounting for chemical reactions of individual components described by a reaction mechanism defined by the user. The sample material is geometrically defined as a series of layers with specified thicknesses, and chemically defined by the material components parameterised with specific physical and chemical properties. The ThermaKin program has been numerically verified and validation studies have been performed using charring and non-charring polymers $[6,7,22,23]$.

The Arrhenius equation is used to calculate the reaction rates in ThermaKin and a set of kinetic parameters must be provided for each reaction. The energy conservation equation is solved by accounting for conduction, energy generation from reactions, convection from adjacent elements, net in-depth absorption of radiation, and energy changes due to net expansion or contraction of the material. The mass conservation equation is solved by accounting for mass production from reactions, advection of gases, and mass transfer connected with overall expansion or contraction of the material.

Heat and mass transfer boundary conditions are defined at the top and bottom surfaces of the computational domain when representing both milligram-scale and bench-scale experimental methods. The bench-scale model required a few assumptions a priori about the heat and mass transfer characteristics of the sample and test procedure. Heat was transferred to the material with a radiation boundary condition set to the external heat flux for the cone calorimeter tests. As the sample material was heated, convective cooling to the atmosphere occurred with a convection coefficient of $10 \mathrm{~W} \mathrm{~m}^{-2} \mathrm{~K}^{-1}$ and a constant ambient temperature of $27^{\circ} \mathrm{C}$ was assumed [24]. More information regarding ThermaKin is available in Ref. [19].

FDS, Comsol and ThermaKin are based on a similar set of energy, mass and species conservation equations. The major differences between the programs, with regard to treatment of the solid-phase pyrolysis, concern the submodel for radiative heat transfer and the way input parameters are entered numerically. In FDS, the time dependence is not prescribed by a polynomial but rather as a ramp, where the user specifies e.g. the thermal conductivity, for some selected temperatures. FDS linearly interpolates the property for temperatures between those specified. For temperatures below and above the edge points, the property is extrapolated assuming it is identical to the prescribed property for the lowest and highest specified temperature values, respectively. This 
approach to specifying temperature dependence is typically more convenient since it matches the experimental methods where a property is normally determined at a number of discrete different temperatures.

Similarly to Thermakin, the solid heat transfer model in FDS is 1-dimensional. However, the CFD code is 3dimentional, enabling three dimensional calculations of heat and mass transport in the gas phase. This is an advantage e.g. for studying flaming conditions in the cone calorimeter, where the flame's finite size will cause a spatially dependent heat transfer from the flame to the surface. FDS, including the pyrolysis model, has also been extensively validated. For further details the reader is referred to the FDS User's Guides [21,23] or the Technical Reference Guides [25].

Comsol is a user-friendly, efficient, finite element method program, where many equations and aspects of physics (heat transfer, mechanical changes, CFD etc.) can be simultaneously coupled together and solved. Heat transfer coupled with mass transfer has been implemented in this program in order to model cone calorimeter or CAMLS tests. As with FDS, temperature-dependent properties are described as linear extrapolations from data point inputs, and finite mass transport of the gases can be implemented in the model. Comsol has already been employed to model cone calorimeter results of polycarbonate [26]. The equations and physics solved by Comsol are similar to those solved by ThermaKin, except that in-depth absorption is not taken into account.

\section{Analysis and Model Development}

\subsection{Milligram-scale Data Analysis and Model Construction}

The TGA data collected in nitrogen were analysed with the ThermaKin, Comsol and FDS programs to determine the reaction mechanism and form a milligram-scale thermal decomposition model. The procedure used to determine the reaction mechanism required an assessment of the number of reactions evident in the resultant curve and the scheme in which the reactions were related. Each individual reaction was handled as a first-order process that involved a single reactant and two products. A generic set of kinetic parameters served as an initial estimation to describe the curve for each reaction. Adjustments to the kinetic parameters were made until the generated curve showed good agreement with the experimental curve for the individual reaction considered. This process was repeated for all reactions to produce a curve that agreed with the entire experimental MLR curve. A more elaborate explanation of the procedure used to determine the effective reaction mechanism for polymers from TGA data is detailed in related work [16].

The reaction mechanism was intended to mathematically mimic the MLR data in the simplest form possible and relied on model-specific kinetics to reproduce the experimental curve obtained with heating rate $10^{\circ} \mathrm{C} \mathrm{min}-1$. The empirically-determined kinetic parameters are not unique for this material, and may change with changing test conditions. However, within the scope of this work it was not possible to quantify this variation. Figure 4 presents indistinguishable performances of the three pyrolysis models based on the same kinetics predicting MLR results for various heating rates. 


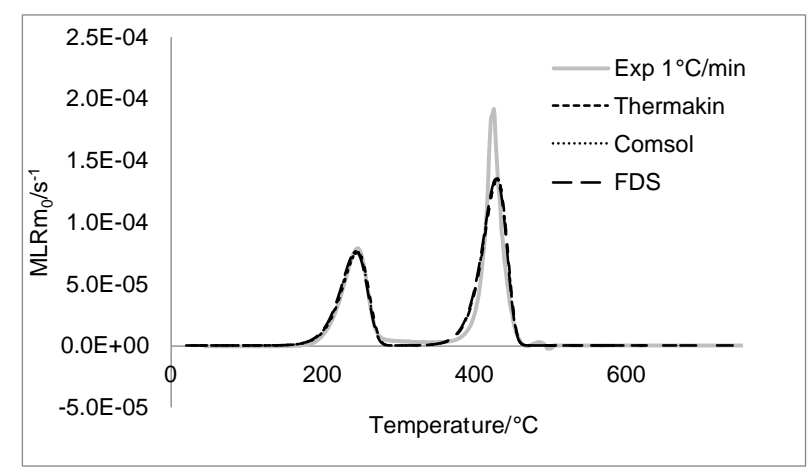

(a)

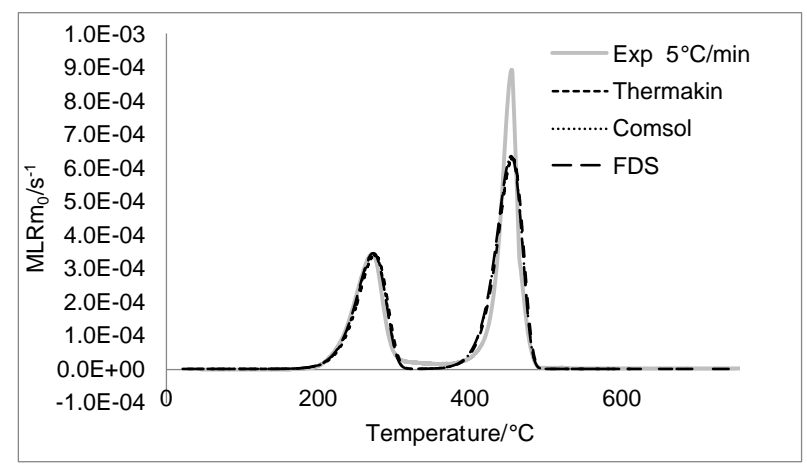

(c)

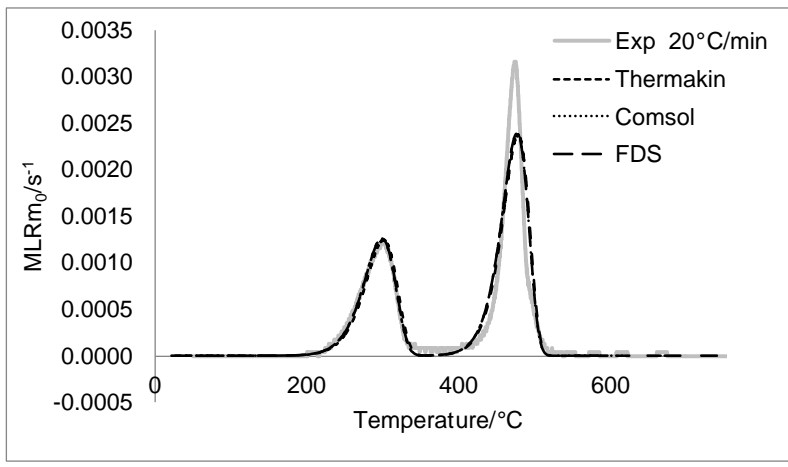

(e)

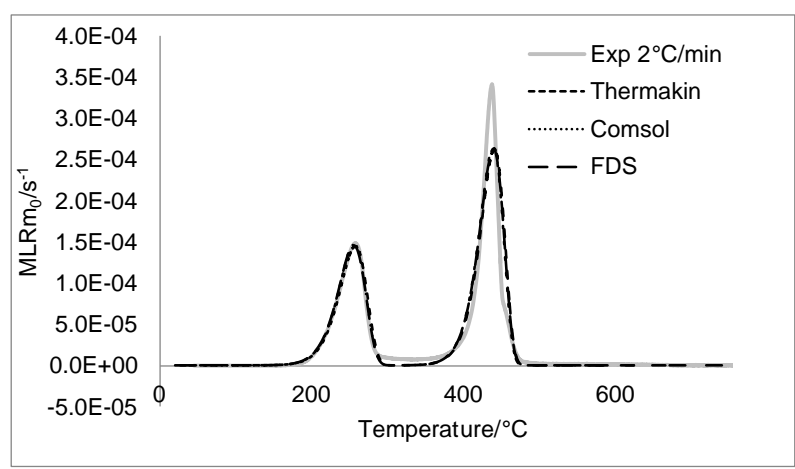

(b)

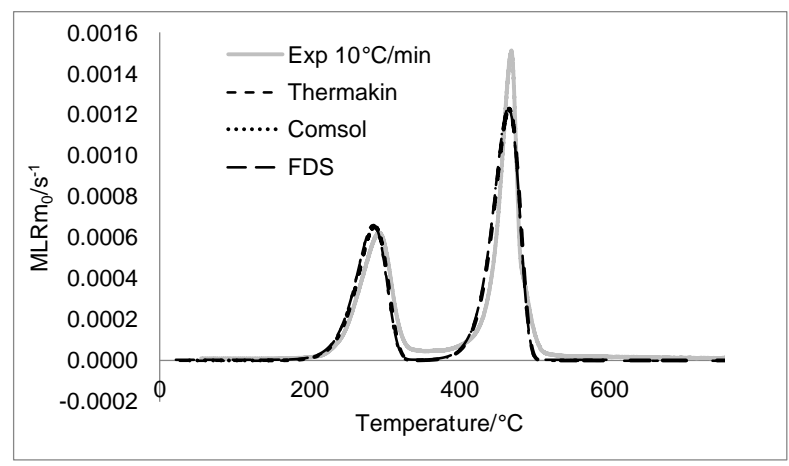

(d)

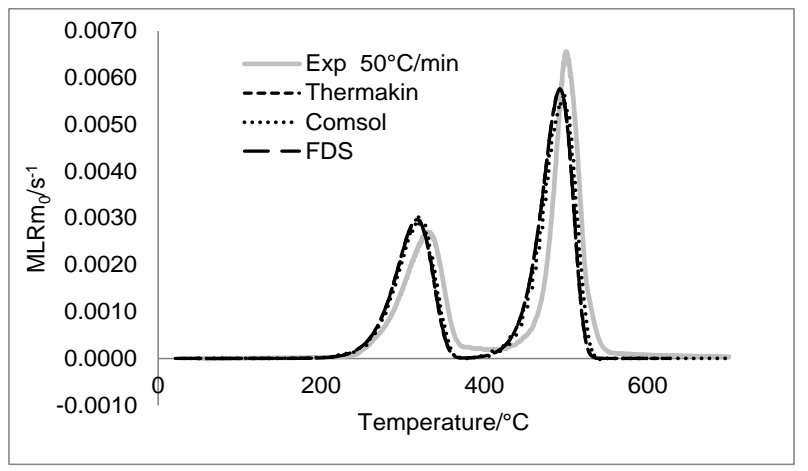

(f) 


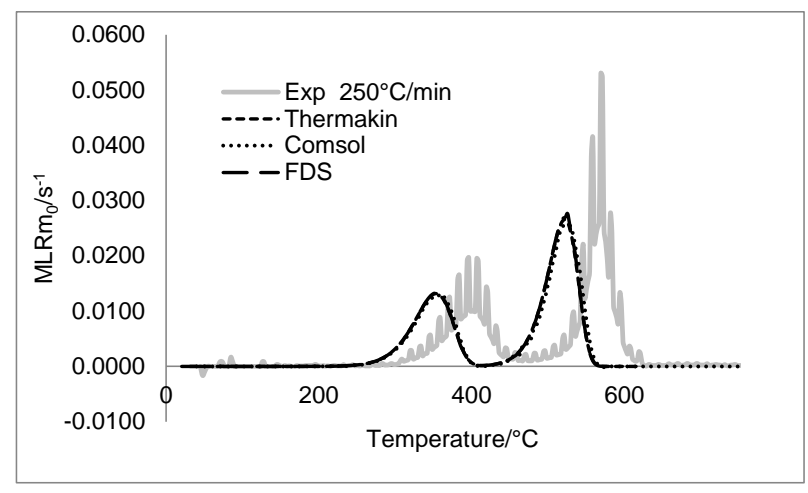

(g)

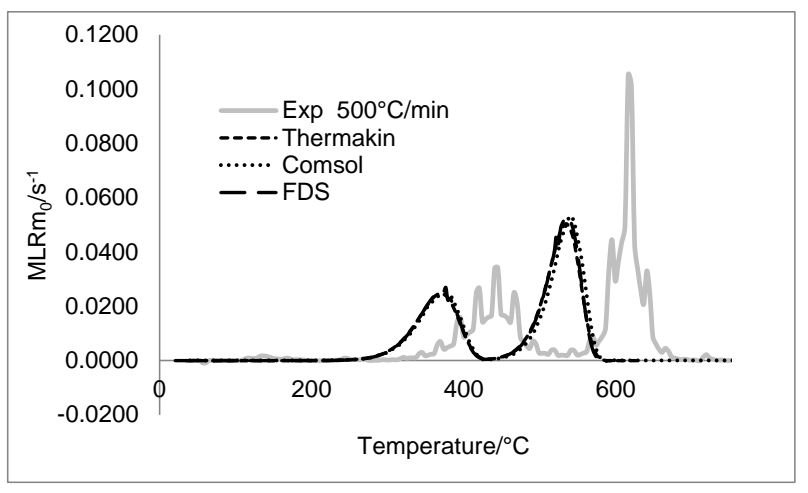

(h)

Figure 4: TGA Normalized Mass Loss Rate experimental data collected in nitrogen at a heating rates of 1, 2, $5,10,20,50,250,500{ }^{\circ} \mathrm{C} \mathrm{min}-1$ presented as a solid grey line and the models prediction presented as dashed lines for ThermaKin, Comsol and FDS

A two-reaction mechanism was found to produce a MLR curve that encompassed all the features of the experimental data as it is presented in Figure 4 (d). The stoichiometry of each step was as follows:

\begin{tabular}{|c|c|c|c|c|c|}
\hline Step one: & $1 \mathrm{PA}$ & $\rightarrow$ & 0.79 PA_r1 & + & $0.21 \mathrm{H}_{2} \mathrm{O} \_\mathrm{g} 1$ \\
\hline Step two: & 1 PA_r1 & $\rightarrow$ & 0.58 PA_r2 & + & 0.42 g2 \\
\hline
\end{tabular}

Where 'PA' denotes the original PE+ATH cable material, 'PA_r1' denotes the intermediate mixture (alumina and $\mathrm{PE})$, ' $\mathrm{H}_{2} \mathrm{O} \_\mathrm{g} 1$ ' is the water released from the decomposition of ATH, 'PA_r2' is the alumina residue and 'g2' is the mixture of hydrocarbon gases evolved from the decomposition of the PE. Each reaction was assumed to follow a first-order process that involved one reactant and two products. A generic set of kinetic parameters served as an initial estimation to describe the curve for each reaction, and these were adjusted until the generated curve showed good agreement with the experimental curve for the individual reaction considered. Table 1 displays the reaction kinetics and heat of reaction that describe the best agreement between the model prediction and the experimental curves.

Table 1: Reaction parameters determined through analysis of milligram-scale data

\begin{tabular}{llll}
\hline Reaction & $A_{r}\left(\mathrm{~s}^{-1}\right)$ & $E_{a}\left(\mathrm{~J} \mathrm{~mol}^{-1}\right)$ & $h_{r}\left(\mathrm{~J} \mathrm{~kg}^{-1}\right)$ \\
\hline 1 & $6.31 \times 10^{9}$ & $1.27 \times 10^{5}$ & $-7.60 \times 10^{5}$ \\
2 & $3.98 \times 10^{16}$ & $2.63 \times 10^{5}$ & $-2.70 \times 10^{5}$ \\
\hline
\end{tabular}

The DSC measurements of heat of reaction $\left(h_{r}\right)$ were obtained as shown in Figure 5 . The baseline was extrapolated and the tangents to the steepest part of the two reaction profiles were extended to the baseline. Integrating the area within the intersection point of the tangent and the baseline provided the heat of decomposition values in J $\mathrm{kg}^{-1}$.

The heat capacity $\left(C_{p}\right)$ of the material was determined using isothermal modulated differential scanning calorimetry (mDSC). The measurements were made every $100{ }^{\circ} \mathrm{C}$ from $100{ }^{\circ} \mathrm{C}$ to $1000{ }^{\circ} \mathrm{C}$ with $10^{\circ} \mathrm{C} \mathrm{min}-1$ ramps 
between each isothermal step. At each temperature, an isothermal step of 10 minutes was used prior the mDSC measurement using a modulation of $\pm 0.5^{\circ} \mathrm{C}$ every $60 \mathrm{~s}$. Results are shown in Table 2 . Before degradation $\left(<672{ }^{\circ} \mathrm{C}\right)$, the heat capacity increased steadily and reached its maximum after the first step of degradation. Then $C_{p}$ decreased and reached a plateau of around $1300 \mathrm{~J} \mathrm{~g}^{-1} \mathrm{~K}^{-1}$, up to $1000{ }^{\circ} \mathrm{C}$.

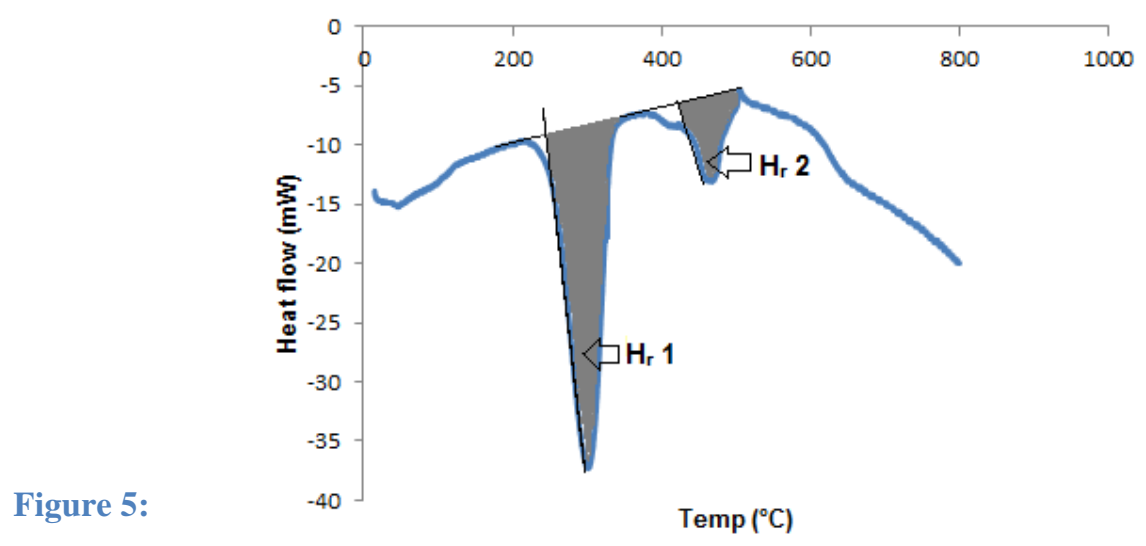

Demonstration of the

method used to obtain heat of decomposition for reactions one and two from DSC data

Table 2: Heat capacity measurements over a range of temperatures

\begin{tabular}{ll}
\hline Temperature/ ${ }^{\circ} \mathrm{C}$ & $\mathrm{C}_{\mathrm{p}} / \mathrm{J} \mathrm{g}^{-1} \mathrm{~K}^{-1}$ \\
\hline $\mathbf{1 0 2}$ & 1745 \\
$\mathbf{2 0 0}$ & 1851 \\
$\mathbf{2 9 9}$ & 2010 \\
$\mathbf{3 9 9}$ & 2217 \\
$\mathbf{4 9 8}$ & 1445 \\
$\mathbf{5 9 7}$ & 1361 \\
$\mathbf{6 9 6}$ & 1354 \\
$\mathbf{7 9 4}$ & 1320 \\
$\mathbf{8 9 2}$ & 1308 \\
\hline 990 & 1299 \\
\hline
\end{tabular}

The thermal conductivity of the material was evaluated using the Hot Disk method and the experiments were duplicated. The experiments were repeatable, except between $130{ }^{\circ} \mathrm{C}$ and $280{ }^{\circ} \mathrm{C}$. In this temperature range, the ATH started to dehydrate and escaping the water vapour may have reduced the thermal contact between the sample and the instrument. With the exception of this particular temperature range, the thermal conductivity steadily decreased from ambient to $380^{\circ} \mathrm{C}$. Above $380^{\circ} \mathrm{C}$, the materials consist exclusively of alumina, $\mathrm{Al}_{2} \mathrm{O}_{3}, \mathrm{which}$ acts as thermal barrier. Its conductivity stayed constant at $0.21 \mathrm{~W} \mathrm{~m}^{-1} \mathrm{~K}^{-1}$ from $380{ }^{\circ} \mathrm{C}$ to $730{ }^{\circ} \mathrm{C}$. 


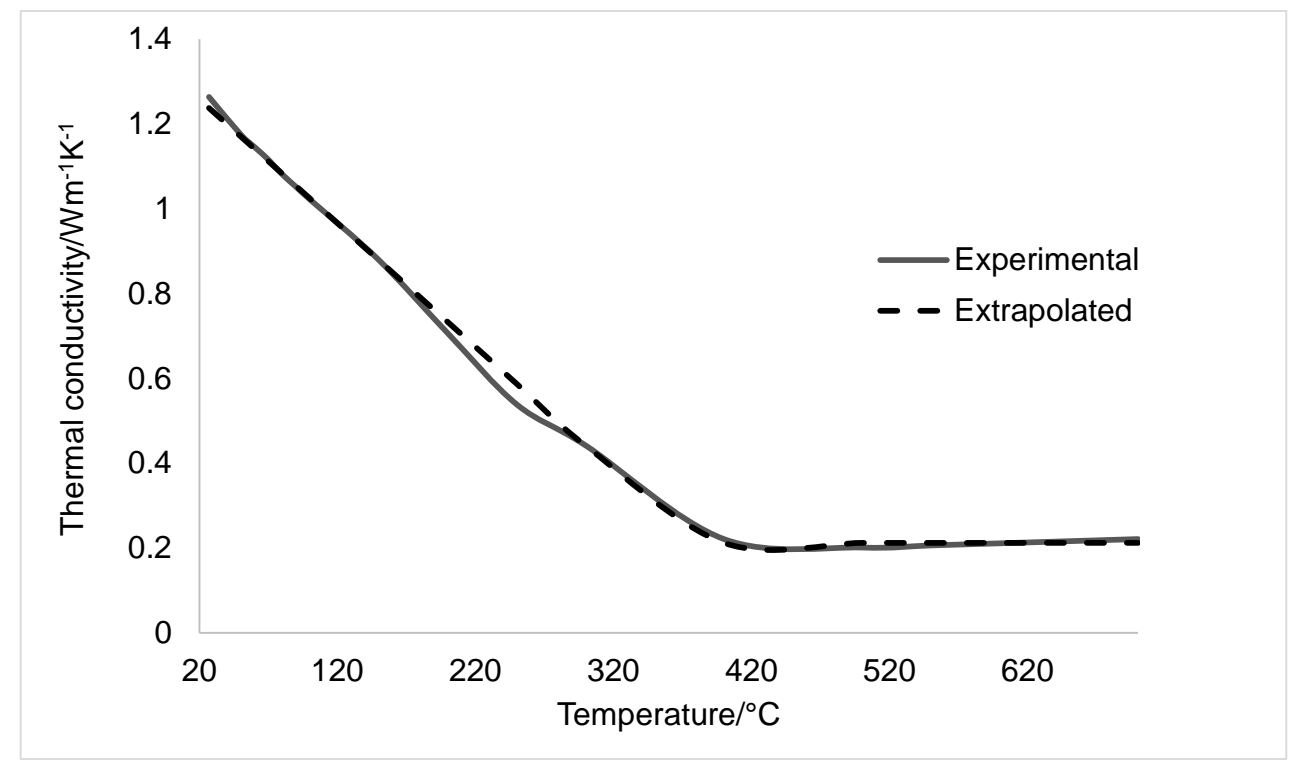

Figure 6: Thermal conductivity of the cable material

The thermal conductivity of the materials was extrapolated from the experimental data and can be expressed as:

Table 3: Thermal conductivity

\begin{tabular}{|c|c|c|}
\hline $\mathrm{k}_{0} / \mathrm{W} \mathrm{m}^{-1} \mathrm{~K}^{-1}$ & 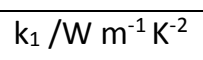 & Temperature range $/{ }^{\circ} \mathrm{C}$ \\
\hline 2.11 & $-2.91 \times 10^{-3}$ & Ambient - 380 \\
\hline 0.21 & & $>380$ \\
\hline
\end{tabular}

\subsection{Infrared properties}

The reflectance spectrum for a $3 \mathrm{~mm}$ thick sample is shown in Figure 7 (dashed line). Due to the thickness, the transmission in Eq. (1) can be neglected. For an irradiation level of $50 \mathrm{~kW} \mathrm{~m}^{-2}$ the temperature of the helical coil in the cone calorimeter is $\approx 750{ }^{\circ} \mathrm{C}$ [17]. Inserting this temperature and using the reflectance spectrum in Figure 7, Eqs. (1) - (3) gives a total reflectivity $\alpha=0.92$. The error introduced in Eq. (2), due to the fact that the spectral absorptivity is determined only in a limited wavelength interval (0.3-17 $\mu \mathrm{m}$ in this study) and not over the entire electromagnetic spectrum, is in the order of $2 \%$ for a black body temperature of $750{ }^{\circ} \mathrm{C}$ [27]. 


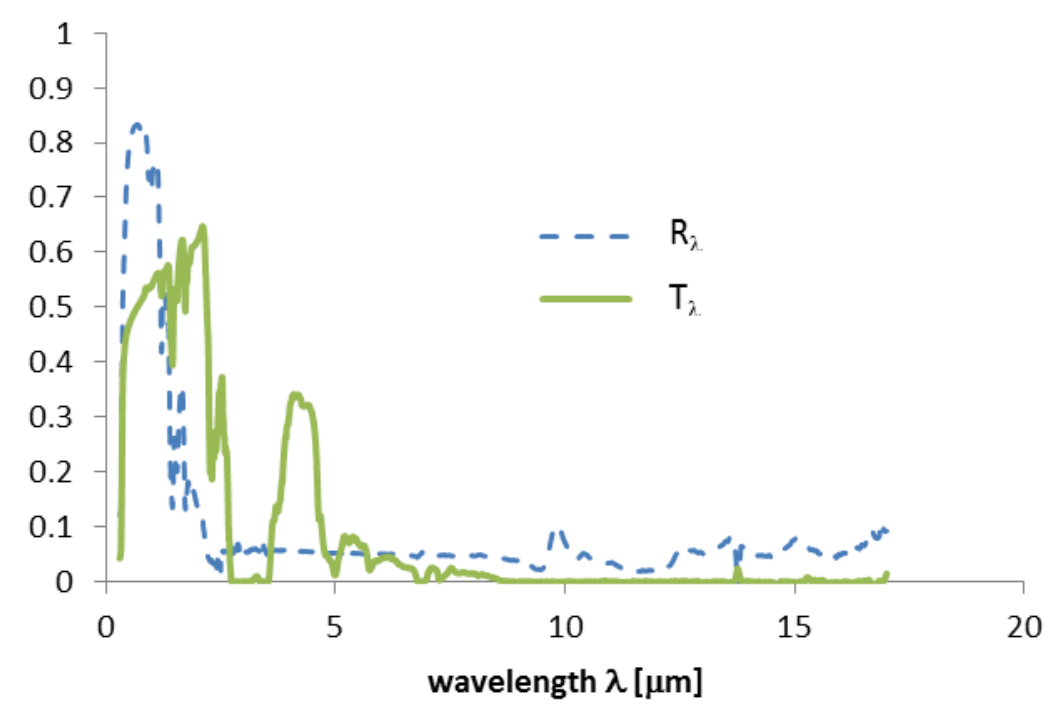

Figure 7: Spectrally resolved reflectivity of a $3.0 \mathrm{~mm}$ thick sample and transmission through a $0.20 \mathrm{~mm}$ thick sample.

The transmittance spectrum for a $0.20 \mathrm{~mm}$ thick sample is shown as the solid line in Figure 7 . The spectrally resolved absorption coefficient, $A_{\lambda}$, is obtained from Eq. (5). However, the transmittance is near zero for certain wavelength intervals, meaning that the signal to noise ratio of the measurement is too low, or zero, so the spectral absorption coefficient cannot be determined at these wavelengths. This is a frequent problem due to the strong infrared absorption in certain spectral regions. Boulet et al. (2014) [28] recently presented results for the full spectrum of transparent PMMA. They handled the spectral regions with low or zero transmission using a method based on the Lorentz oscillators model [29], where reflectivity data was also used. In this work an alternative, and very approximate, approach is taken where we set $A_{\lambda}=50000 \mathrm{~m}^{-1}$ for the spectral ranges where the signal to noise ratio is too low. This value is also used by FDS as the default value. The corresponding skin depth is $40 \mu \mathrm{m}$ which can almost be considered as absorption at the surface. The spectral ranges where $A_{\lambda}$ must be replaced by a fixed value are mainly $2.7-3.1 \mu \mathrm{m}$ and above $9 \mu \mathrm{m}$. Using this substitution method for the undetermined $A_{\lambda}$, and using Eqs. (7) and (9), a total absorption coefficient of $A=8300 \mathrm{~m}^{-1}$ is obtained, with a skin depth of $220 \mu \mathrm{m}$.

\subsection{Calorimeter measurement in nitrogen}

Figure 9 shows the normalised mass loss and normalised mass loss rate (MLR) curves for the tested materials. The experiments were run as triplicates. The oxygen concentration was monitored during the experiments and is shown in Figure 8. The experimental setup allowed repeatable conditions for the pyrolysis with oxygen concentrations between 1.5 and $2 \%$ for the entire duration of the tests. 


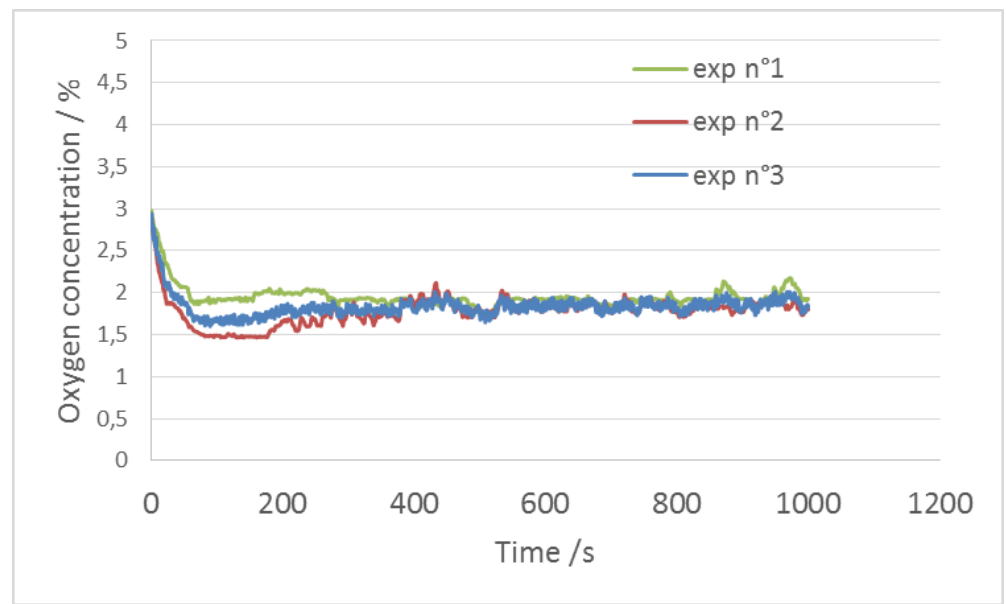

Figure 8: Oxygen concentration during pyrolysis experiments

The experimental mass loss curves showed good agreement between the experiments: the final mass was $73.98 \%$, on average, with a standard deviation of $1.67 \%$, and the time for the onset of degradation was always between 32- $39 \mathrm{~s}$. The peak of mass loss rate (PMLR) and the time to pMLR were very repeatable for the three experiments.

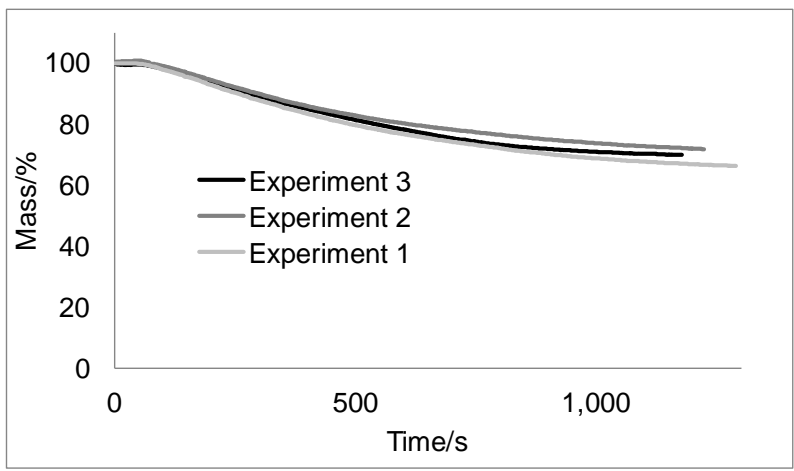

(a)

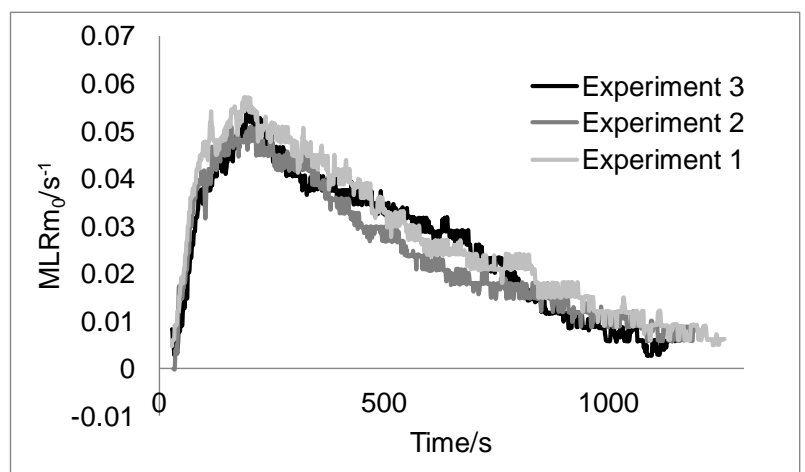

(b)

Figure 9: Mass loss calorimeter results for incident heat flux of $50 \mathrm{~kW} \mathrm{~m}^{-2}$ (a) Mass loss curves (b) Mass Loss Rate curves

\section{Bench-scale models}

The fully parameterised bench-scale models were used to generate MLR predictions for incident heat fluxes of 50 $\mathrm{kW} \mathrm{m} \mathrm{m}^{-2}$.

Table 4: Thermal properties of all components defined in bench-scale pyrolysis model

\begin{tabular}{|c|c|c|c|c|c|}
\hline Component & $\rho / \mathrm{kg} \mathrm{m}^{-3}$ & $c / \mathrm{J} \mathrm{kg}^{-1} \mathrm{~K}^{-1}$ & $\kappa / \mathrm{W} \mathrm{m}^{-1} \mathrm{~K}^{-1}$ & $\alpha / m^{-1}$ & $\epsilon$ \\
\hline Cable & $1560^{\mathrm{a}}$ & $1900-0.3197 \mathrm{~T}+3 \mathrm{e}-4 \mathrm{~T}^{2} \mathrm{~b}$ & $2.8212-6.6 \mathrm{e}-3 \mathrm{~T}+4 \mathrm{e}-6 \mathrm{~T}^{2 c}$ & $8300^{d}$ & $0.92^{\mathrm{d}}$ \\
\hline Cable $_{\text {int }}$ & $1240^{\mathrm{g}}$ & $1900-0.3197 \mathrm{~T}+3 \mathrm{e}-4 \mathrm{~T}^{2} \mathrm{~b}$ & $2.8212-6.6 \mathrm{e}-3 \mathrm{~T}+4 \mathrm{e}-6 \mathrm{~T}^{2 g}$ & $8300 \mathrm{~g}$ & $0.92^{\mathrm{g}}$ \\
\hline Cablechar & $720^{\mathrm{b}}$ & $1900-0.3197 \mathrm{~T}+3 \mathrm{e}-4 \mathrm{~T}^{2} \mathrm{~b}$ & $2.8212-6.6 \mathrm{e}-3 \mathrm{~T}+4 \mathrm{e}-6 \mathrm{~T}^{2 g}$ & $8300 \mathrm{~g}$ & $0.92^{\mathrm{g}}$ \\
\hline Cable $_{\text {vol }}$ & $720^{\mathrm{e}}$ & $1900-0.3197 \mathrm{~T}+3 \mathrm{e}-4 \mathrm{~T}^{2} \mathrm{~b}$ & $2.8212-6.6 \mathrm{e}-3 \mathrm{~T}+4 \mathrm{e}-6 \mathrm{~T}^{2} \mathrm{e}$ & $8300 \mathrm{~g}$ & $0.92^{\mathrm{e}}$ \\
\hline Insulation & $890^{f}$ & $1070^{\mathrm{f}}$ & $0.26^{f}$ & $8300 \mathrm{~g}$ & $0.88^{g}$ \\
\hline
\end{tabular}

${ }^{a}$ Measured directly 
${ }^{b}$ Determined from STA assuming no change in volume

${ }^{\mathrm{c}}$ Determined by Hot Disc method

${ }^{d}$ Determined from dispersive and non-dispersive spectrometers and integrating spheres

e Assumed not to contribute to model

${ }^{f}$ Provided by manufacturer

g Estimated values

In the Comsol and FDS modelling, the specific heat and thermal conductivity were implemented as temperature dependent properties. Figure 10 shows the temperature dependence used in the modelling.

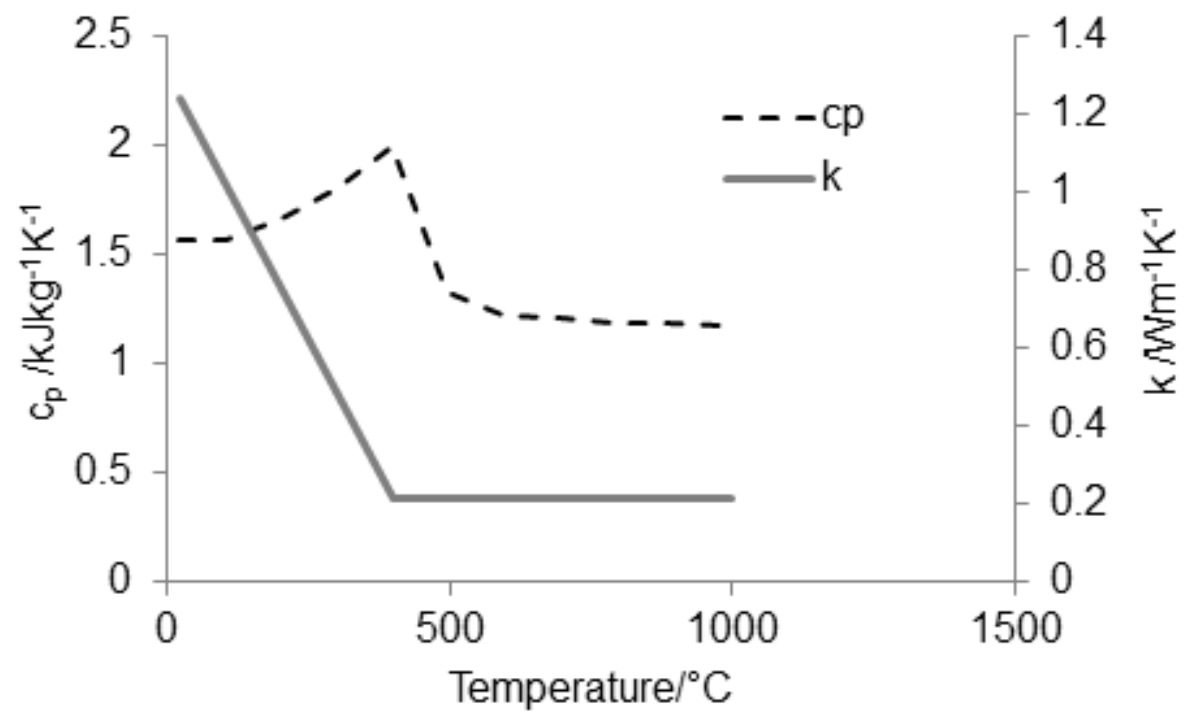

Figure 10: Temperature dependence of specific heat and thermal conductivity used in the Comsol and FDS modeling. 


\subsection{Comparison of simulations between Thermakin, Comsol and FDS}

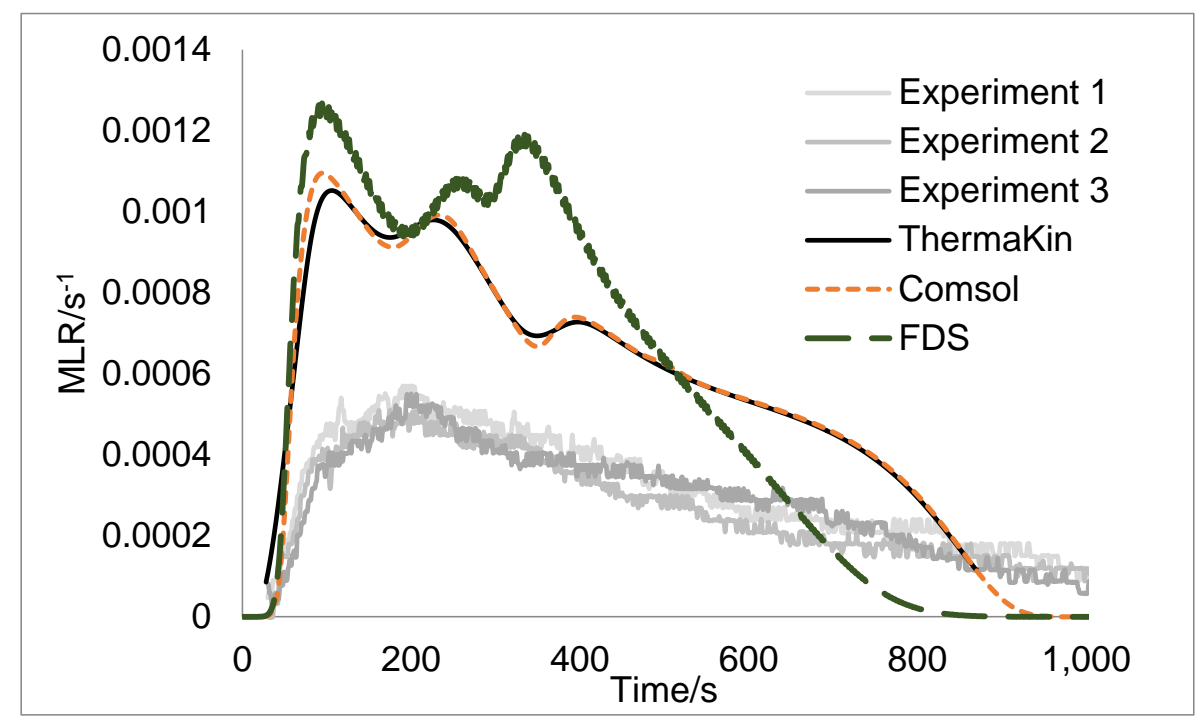

Figure 11: Mass loss rate curves as modelled by Thermakin, Comsol and FDS

Figure 11 shows MLR curves as modelled by the three different numerical tools: Thermakin, Comsol and FDS. Models were supplied with the same parameters, as in Table 4. The characteristic values of the curves are the time taken to reach mass loss rate of $1 \mathrm{~g} \mathrm{~s}^{-1} \mathrm{~m}^{-2}(\mathrm{tML})$, the peak mass loss rate (PMLR) and the total time of pyrolysis (tPYR), calculated as the difference between tML and the time mass loss rate falls below $3 \mathrm{~g} \mathrm{~s}^{-1} \mathrm{~m}^{-2}$ at the end of the test [30]. The tML values of the simulated graphs are within $\pm 1 \%$ of each other. First, second and third PMLR of FDS is simulated around $17 \%, 5 \%$ and $55 \%$ higher than in Comsol and ThermaKin. The tPYR of FDS differs from the other simulations up to $27 \%$. Although all models predict the tMLR with good agreement with the experimental curve $( \pm 1 \%)$ there is a lack of agreement with the remaining features of the experimental curve (PMLR is overshot by around $100 \%$ and tPYR is under-predicted by around $40 \%$ by FDS and $10 \%$ by Comsol and Thermakin).

\subsection{Comparison between models and experiments}

Up to this point, the gas transport coeffficient in all models was assumed to be $1 \times 10^{-5} \mathrm{~m}^{2} \mathrm{~s}^{-1}$, to represent the condition where all pyrolysis effluents leave the sample instantly. However, the material tested in this study contained a significant proportion of ATH, which decomposes to form alumina when heated. Since there is evidence that the freshly formed alumina could change the diffusivity/permeability of the material [31], adjustments were made to the gas transport coefficient used in the models.

The hypothesis of limiting mass transport hypothesis was proposed, because it was thought that the mass transport may have been so slow that it significantly reduced the gasification mass loss rate. This is supported by the data present in Figure 12, where the thermal transport submodel correctly predicts the temperature of the base of the sample. As shown in Figure 12 the thermal transport submodel is not sensitive to changes in gas transport coefficient for either ThermaKin or Comsol. 


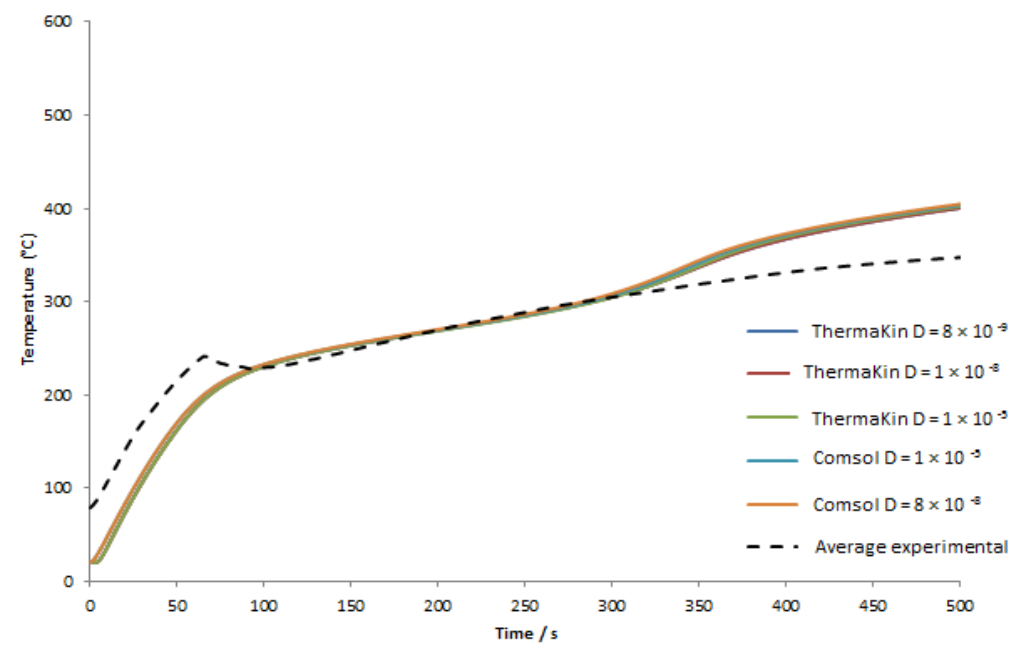

Figure 12: Experimental temperature profile collected for incident heat flux of $50 \mathrm{~kW} \mathrm{~m}^{-2}$ plotted as dashed line and predicted temperature profiles plotted as solid lines

When the gas transport coefficient was changed to $8 \times 10^{-9} \mathrm{~m}^{2} \mathrm{~s}^{-1}$ prediction of experimental MLR curve was improved significantly, as seen in Figure 13. Gas transport coefficient in the solid phase is not available in FDS, so those results are not included in this comparison.

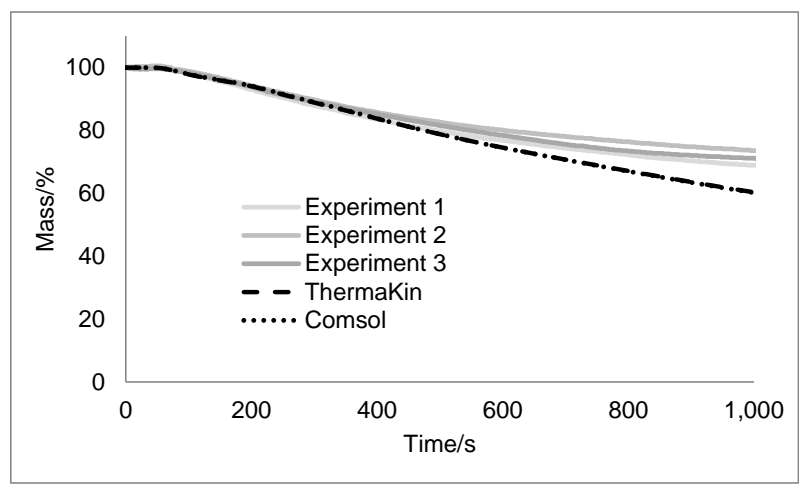

(a)

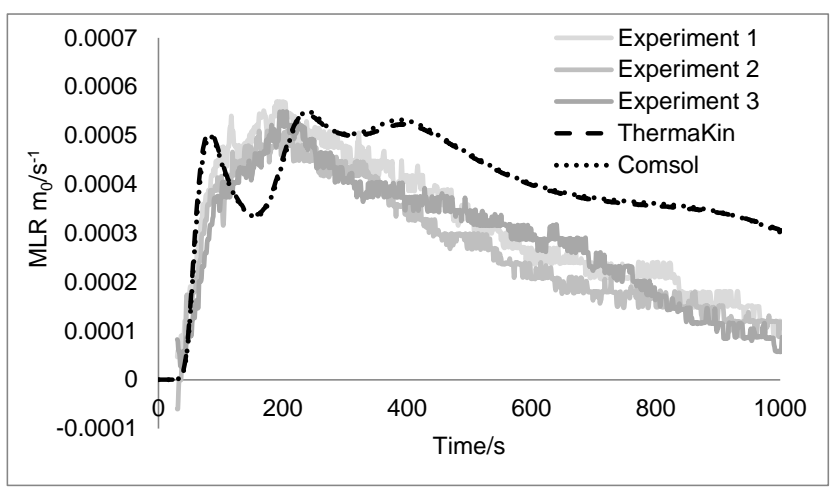

(b)

Figure 13: Predicted ML and MLR curves plotted as dashed lines with three experimental ML and MLR

$$
\text { curves at heat flux } 50 \mathrm{~kW} \mathrm{~m}^{-2} \text { (a) ML curves (b) MLR curves }
$$

Comparison of the simulations and the experiments in the gasification apparatus is based on the material's mass loss rate (MLR). The fully parameterised bench-scale models were used to generate MLR predictions for incident heat fluxes of $50 \mathrm{~kW} \mathrm{~m}^{-2}$. The MLR curve predicted by the model is plotted with the experimental data curves in Figure 13. Table 5 summarises the characteristic values and times associated with the experimental MLR data and the model predictions to demonstrate the agreement between the predicted curves and experimental data. 
Table 5: Characteristic times and values for experimental and predicted Comsol and Thermakin MLR curves

\begin{tabular}{lllc}
\hline Experimental Value & $50 \mathrm{~kW} \mathrm{~m}^{-2}$ & & \\
& Exp. & Model & Difference/\% \\
\hline $\mathrm{tML} / \mathrm{s}$ & 47 & 51 & 9 \\
$\mathrm{PMLR} / \mathrm{s}^{-1}$ & $5.43 \times 10^{4}$ & $5.45 \times 10^{4}$ & $<1$ \\
$\mathrm{tPMLR} / \mathrm{s}$ & 199 & 237 & 19
\end{tabular}

As shown in Figure 13, both models predict tML and PMLR well. There is also a significant improvement in prediction of tPMLR. The dips at around $200 \mathrm{~s}$ in the simulated data result from the simulation predicting that the two gases are released separately with little overlapping. This dip is not evident on the experimental data, most likely as there is overlapping as the two gases are released. Just after $320 \mathrm{~s}$ the models slightly overpredict the experimental results by about $12 \%$. This disagreement could possibly be explained by the fact that it is difficult to accurately measure the properties of decomposing material.

\section{Conclusions}

Milligram-scale experiments were conducted to determine the kinetics and thermodynamics of the reactions occurring during anaerobic thermal degradation of cable sheathing. For the milligram-scale decomposition, the three models were used, based on the same physical principles, and it is gratifying to see that the results from identical input data are indistinguishable, so the choice of the model between FDS, Comsol and ThermaKin is less significant. Based on the agreement between the models representing the milligram-scale experiments and the experimental data, it appears that the reaction kinetics of the thermal degradation process was accurately represented by the reaction mechanism implemented in the model. The agreement between the bench-scale MLR curves and each models' predictions is poorer than for the milligram-scale. On the bench scale, the complexity of the description of the material and testing conditions are more detailed. All physical and optical features of the components, which were ignored in milligram-scale simulations, play a role on the bench scale. Also, parameters such as mass transport coefficient, absorption coefficient or temperature dependent values cannot be input the same way in these models which could potentially explain the difference in results presented. Additionally, physical properties of the solid (such as heat capacity and thermal conductivity) are assumed in this study to be only a function of temperature. In reality, they are a function of both temperature and composition. The composition is, in turn, related to the rate of chemical transformations and, therefore, time. This approach, of only relating the physical properties to temperature forces physical property changes to occur prior to the corresponding chemical transformations in the gasification simulation, which may, at least partially, explain the discrepancies between the simulation and experiment.

Generally, with accurate input parameters, the choice of the model between FDS, Comsol and ThermaKin is less significant, since they use comparable physical descriptions of the phenomena. 
Building on the results of this investigation, including independent measurement of most of the parameters describing PE and ATH, future work will be primarily concerned with predicting HRR and MLR curves from flaming experiments in the cone calorimeter.

Additionally, for large scale fire simulations, an understanding of the effects of material properties on the mass loss rate can be useful for achieving better understanding of the fire behaviour. The condensed phase pyrolysis models of cable sheathing developed in this study could be used as sub-models in full scale CFD code to predict the burning processes in, for example, EN 50399 large scale bunched vertical wire cable test.

\section{Acknowledgements}

Maria Tengelin Nilsson and Anne Andersson at SP Measurement Technology performed the optical characterization.

Camille Le Bras at $\mathrm{R}^{2}$ Fire conducted controlled atmosphere mass loss calorimetry.

The research leading to these results has received funding from the European Union's Seventh Framework Programme (FP7/2007-2013) under grant agreement $n^{\circ} 308391$. Bertrand Girardin and Fiona Hewitt are grateful for PhD studentships supported by this project.

\section{References}

[1] Cheng LH, Ueng TH, Liu CW. Simulation of ventilation and fire in the underground facilities. Fire Safety Journal $2001 ; 36: 597-619$.

[2] Leung CH, Staggs JEJ, Brindley J, McIntosh AC, Whiteley RH. The effects of an inert central core on the thermal pyrolysis of an electrical cable. Fire Safety Journal 2000; 34:143- 168.

[3] Babrauskas V, editor. Ignition Handbook: Principles and Application to Fire Safety Engineering, Fire Investigation, Risk Management and Forensic Science. Fire Science Publishers, 2003.

[4] Babrauskas V, Proceedings Fire and Materials Conference 2001; 39-51.

[5] Camino G, Maffezzoli A, Braglia M, De Lazzaro M, and Zammarano M. Effect of hydroxides and hydroxycarbonate structure on fire retardant effectiveness and mechanical properties in ethylene-vinyl acetate copolymer. Polymer Degradation and Stability 2001; 74:457 - 464.

[6] Stoliarov SI, Crowley S, Lyon RE, Linteris GT. Prediction of the burning rates of non-charring polymers. Combustion Flame 2009; 156:1068-1083.

[7]Stoliarov SI, Safronava N, Lyon RE. The effect of variation in polymer properties on the rate of burning. Fire and Materials 2009; 33:257-271.

[8] Staggs JEJ. Heat and mass transport in developing chars. Polymer Degradation and Stability 2003; 82: 297 - 307.

[9] Di Blasi C, Modeling and simulation of combustion processes of charring and non-charring solid fuels. Progress in Energy and Combustion Science 1993; 19:71 - 104.

[10]Kempel F, Schartel B, Linteris G T, Stoliarov SI, Lyon RE, Walters RN, Hofmann A. Prediction of the mass loss rate of polymer materials: Impact of residue formation. Combustion and Flame 2012; 159:2974-2984. 
[11]Huang X, Nakamura Y, Williams FA. Ignition-to-spread transition of externally heated electrical wire. Proceedings of the Combustion Institute 2013; 34:2505-2512.

[12] Matala A, Hostikka S. Pyrolysis Modelling of PVC Cable Materials. Fire Safety Science - Proceedings of the Tenth International Symposium, International Association for Fire Safety Science 2011; 917-930.

[13] Matala A, Hostikka S. Fire modelling of flame retardant electrical cable, Proceedings Fire and Materials Conference $2011 ; 583-596$.

[14] McGrattan K, McDermott R, Mell W, Forney G, Hostikka S, Matala A. Modeling the burning of complicated objects using Lagrangian particles, 12th International Conference on Fire Science and Engineering: Interflam 2010; 743-754.

[15] McKinnon MB, Stoliarov SI, Witkowski A. Development of a pyrolysis model for corrugated cardboard. Combustion and Flame 2013; 160:2595-2607.

[16] Li J, Stoliarov SI. Procedure of Measurement of Kinetics and Thermodynamics of Non-charring Polymers. Combustion and Flame 2013: 160(7):1287-1297.

[17] Försth M, Roos A. Absorptivity and its dependence on heat source temperature and degree of thermal breakdown. Fire and Materials 2011; 35(5):285-301.

[18] Boulet P, Parent G, Acem Z, Collin A, Försth M, Bal N, Rein G, Torero J. Radiation emission from a heating coil or a halogen lamp on a semitransparent sample. International Journal of Thermal Sciences 2014; 77:223-232.

[19] Stoliarov SI, Leventon IT, Lyon RE. Two-dimensional Model of Burning for Pyrolyzable Solids, Federal Aviation Administration, Technical Note DOT/FAA/TC-TN12/59, 2013.

[20] COMSOL Multiphysics, www.comsol.com, website accessed 07/06/2013.

[21] McGrattan K, Hostikka S, McDermott R, Floyd J, Weinschenk C, Overholt K. Fire Dynamics Simulator (Version 6) User's Guide, National Institute of Standards and Technology Special Publication, 1019, 2013.

[22] Lyon RE, Safronava N, Stoliarov SI. The Role of Thermal Decomposition Kintetics in the Burning of Polymers. Interflam, Interscience Communications 2010; 463-474.

[23] Stoliarov SI, Crowley S, Walters RN, Lyon RE. Prediction of the burning rates of charring polymers. Combustion Flame 2010; 157:2024-2034.

[24] Staggs JEJ, Whiteley RH. Modelling the combustion of solid-phase fuels in cone calorimeter experiments. Fire Materials 1999; 23:63-69.

[25] McGrattan K, Hostikka S, McDermott R, Floyd J, Weinschenk C, Overholt K. Fire Dynamics Simulator Technical Reference Guide, Volume 3: Validation, NIST Special Publication 1018, Sixth Edition, 2013.

[26] Statler Jr. DL, Gupta RK. Finite Element Analysis on the Modeling of Heat Release Rate as Assessed by a Cone Calorimeter of Char Forming Polycarbonate, Proceedings of the COMSOL Conference, Boston, 2008.

[27] Försth M, Möller K. Enhanced absorption of fire induced heat radiation in liquid droplets. Fire Safety Journal $2013 ; 55: 182-196$. 
[28]Boulet P, Gérardin J, Acem Z, Parent G, Collin A, Pizzo Y, Porterie B. Optical and radiative properties of clear PMMA samples exposed to a radiant heat flux. International Journal of Thermal Sciences 2014; 82:1-8.

[29] Modest M, Radiative Heat Transfer, $2^{\text {nd }}$ Edition, Academic Press, 2003.

[30] Lyon RE, Janssens ML. Polymer Flammability. Encyclopedia of Polymer Science \& Engineering (on-line edition), Wiley, New York, 2005.

[31] Nair AB, Kurian P, Joseph R. Effect of aluminium hydroxide, chlorinated polyethylene, decabromo diphenyl oxide and expanded graphite on thermal, mechanical and sorption properties of oil-extended ethylene-propylenediene terpolymer rubber. Materials and Designs 2012; 40:80-89. 